\title{
Impaired glucose tolerance, Type II diabetes mellitus and carotid atherosclerosis: prospective results from the Bruneck Study
}

\author{
E. Bonora ${ }^{1}$, S. Kiechl ${ }^{2}$, F. Oberhollenzer ${ }^{3}$, G.Egger ${ }^{3}$, R.C. Bonadonna ${ }^{1}$, M.Muggeo ${ }^{1}$, J. Willeit ${ }^{2}$ \\ ${ }^{1}$ Department of Endocrinology and Metabolic Diseases, University of Verona Medical School, Verona, Italy \\ ${ }^{2}$ Department of Neurology, University of Innsbruck Medical School, Innsbruck, Austria \\ ${ }^{3}$ Department of Internal Medicine, Hospital of Bruneck, Bruneck, Italy
}

\begin{abstract}
s
Aims/hypothesis. Cardiovascular disease is a wellknown severe complication of impaired glucose tolerance and Type II (non-insulin-dependent) diabetes mellitus. The independent contribution of glucose intolerance to cardiovascular disease and the underlying pathogenic mechanisms are still, however, not clear. Methods. In this prospective population-based study, 826 subjects aged 40-79 years underwent high resolution duplex ultrasound examinations of carotid arteries and extensive clinical and laboratory screenings for potential vascular risk factors at baseline and 5 years later. The ultrasound protocol involved measurements of maximum axial diameter of atherosclerotic plaques, if any, in common and internal carotid arteries on both sides and enable differentiation of two main stages in carotid artery disease, termed early non-stenotic and advanced stenotic atherosclerosis. Intima-media thickness was assessed at the follow-up examination.

Results. Type II diabetes and, to a lesser extent, impaired glucose tolerance were found to be statistically
\end{abstract}

significant risk predictors of 5-year changes in carotid atherosclerosis. These associations were in part independent of other vascular risk factors typically clustering with glucose intolerance. Both impaired glucose tolerance and Type II diabetes mellitus were not independently related to early non-stenotic atherosclerosis. In contrast, Type II diabetes mellitus was the strongest single risk predictor of advanced stenotic atherosclerosis [odds ratio 5.0 (95\% confidence intervals 2.3-11.1)] and impaired glucose tolerance was of relevance as well [odds ratio 2.8 $(1.2-6.4)](p<0.001)$.

Conclusion/interpretation. Impaired glucose tolerance and, to a greater extent, Type II diabetes were strong independent predictors of advanced carotid atherosclerosis in our prospective population-based study. [Diabetologia (2000) 43: 156-164]

Keywords Impaired glucose tolerance, Type II diabetes mellitus, atherosclerosis, carotid arteries, cardiovascular risk factors.
Atherosclerotic vascular diseases such as myocardial infarction, stroke and lower extremity arteriopathy are well-known severe complications of impaired glu-

Received: 29 July 1999 and in revised form: 23 September 1999

Corresponding author: Prof. E. Bonora, Endocrinologia e Malattie del Metabolismo, Ospedale Civile Maggiore, Piazzale Stefani, 1, I-37126 Verona, Italy

Abbreviations: IMT, Intima-media thickness; CA, carotid atherosclerosis; WHR, waist:hip ratio; WHO, World Health Organization; Lp(a), lipoprotein (a); OR, odds ratio. cose tolerance (IGT) and Type II (non-insulin-dependent) diabetes mellitus [1-7] and account for up to $60-70 \%$ of deaths in diabetic subjects [8]. Impaired glucose tolerance and Type II diabetic patients often have, however, multiple metabolic, haemodynamic and haemocoagulative defects such as high triglycerides and low HDL cholesterol, high blood pressure and high fibrinogen [9-15], which are cardiovascular risk factors in themselves [16]. These defects can precede the development of glucose intolerance by several years $[17,18]$. Thus, the independent contribution of glucose intolerance and its bio- 
chemical hallmark, i.e. hyperglycaemia, to the clinical manifestations of atherosclerosis is still disputed [19-22].

The current prospective population-based study was designed to examine the role of IGT and Type II diabetes in carotid atherosclerosis. Differential effects of IGT and Type II diabetes on various stages of atherosclerosis and on the aetiologic relevance of hyperglycaemia and metabolic abnormalities typically associated with glucose intolerance was a special focus.

\section{Materials and methods}

Subjects. The Bruneck Study is a prospective population-based survey on atherosclerosis and its risk factors carried out in Bruneck, a small town of about 13,500 people in north-eastern Italy. As previously reported [23], the baseline evaluation was carried out between July and November 1990 on subjects aged 40 to 79 years. Of the 4793 subjects of the appropriate age range, 125 men and 125 women from each of the fifth to the eighth decade of age were selected randomly for inclusion. Of the 1000 subjects invited to participate, 936 volunteered after the purposes and the modalities of the study had been carefully presented. Complete data were available in 919 subjects (91.9\% of the sample extracted from the general population).

From July to October 1995 the cohort was re-evaluated [24]. Of the original population sample, 62 subjects had died, 1 had moved away and could not be traced and 30 declined to participate in the follow-up study. Thus, the latter was $96.5 \%$ complete among survivors $(n=826$ out of 856$)$. The protocol was approved by the ethics committee of the Verona City Hospital.

Clinical data. In each subject information about cigarette smoking, alcohol consumption, physical activity and socio-economic status was collected by a standardized questionnaire, as described previously [23, 24].

Subjects were regarded as diabetic if they were receiving insulin or oral hypoglycaemic agents or both or when their fasting plasma glucose exceeded $7.8 \mathrm{mmol} / \mathrm{l}$ or if their plasma glucose $2 \mathrm{~h}$ after oral glucose loading exceeded $11.1 \mathrm{mmol} / \mathrm{l}$ [25]. Impaired glucose tolerance was diagnosed when plasma glucose $2 \mathrm{~h}$ after glucose load exceeded $7.8 \mathrm{mmol} / 1$ [25]. Type II diabetes was diagnosed according to World Health Organisation (WHO) criteria [25].

Physical examination data. Weight (to the nearest $0.5 \mathrm{~kg}$ ) and height (to the nearest $0.5 \mathrm{~cm}$ ) were measured after an overnight fast and while the subjects were wearing only undergarments. Body mass index (BMI) was calculated as weight $(\mathrm{kg})$ divided by height $(\mathrm{m})^{2}$. Waist and hip circumferences (to the nearest $0.5 \mathrm{~cm}$ ) were measured by a plastic tape meter at the level of the umbilicus and of the greater trochanters, respectively and waist to hip ratio (WHR) was calculated.

Blood pressure was measured with a standard mercury sphygmomanometer on the left arm, after the subjects had been seated for at least $10 \mathrm{~min}$. Mean values were determined from two independent measurements taken at intervals greater than 10 min. Hypertension was defined by a systolic blood pressure of $160 \mathrm{mmHg}$ or higher or a diastolic blood pressure of $95 \mathrm{mmHg}$ or higher or the use of anti-hypertensive treatment or more of them [26].
Laboratory data. In the morning, after an overnight fast, blood samples were collected for the measurement of glycated haemoglobin $\left(\mathrm{HbA}_{1 \mathrm{c}}\right)$, factor $\mathrm{V}$ Leiden mutation, plasma concentrations of glucose, serum concentrations of total, LDL and HDL cholesterol, triglycerides, apolipoproteins A1 and B, $\mathrm{Lp}(\mathrm{a})$, ferritin, fibrinogen and antithrombin III. Thereafter, a 75-g oral glucose load (OGTT) was given to all subjects, except for those with well established diabetes, and venous blood was collected after $2 \mathrm{~h}$ for the measurement of plasma glucose. Biochemical variables were assessed by standard and qualitycontrolled procedures [27-37].

Assessment of carotid atherosclerosis. At baseline and 5 years later carotid atherosclerosis (CA) was determined by high-resolution B-mode ultrasound (ATL UM8, Advanced Technology Laboratories, Bothel, Washington, D.C., USA), as described previously [23]. All measurements were carried out by a single specialist physician (J. Willeit), who had no information on the results of the first evaluation and was blind to all clinical and laboratory characteristics. Images were recorded on a videotape. Briefly, the scanning protocol included imaging of the common and internal carotid arteries in multiple longitudinal and transverse planes. The near and far walls at each of four well-defined imaging sites of both carotid arteries were explored: proximal common carotid artery: 15 to $30 \mathrm{~mm}$ proximal to the carotid bulb; distal common carotid artery: less than $15 \mathrm{~mm}$ to the carotid bulb; proximal internal carotid artery: carotid bulb and the initial $10 \mathrm{~mm}$ of the vessel; distal carotid artery: more than $10 \mathrm{~mm}$ above the flow divider [38]. Atherosclerotic lesions were defined by two ultrasound criteria: (1) wall surface (protrusion into the lumen or roughness of the arterial boundary) and (2) wall texture (echogenicity). In all eight regions of interest the maximum axial diameter of plaques, if any, was measured (in $\mathrm{mm}$ ) and the measurements summed to obtain an atherosclerosis score [38]. Maximum intima-media thickness (IMT) was measured in 1995 at the far wall of the common carotid arteries. This surrogate of definite atherosclerosis was defined as the distance between the lumen-intima interface and the leading edge of the intima-adventitia interface. Values applied are averages of the IMT in the right and left common carotid arteries.

Based on the follow-up examination, we assessed 5-year changes in the vascular status. In particular, we evaluated the change in the atherosclerosis score during follow-up. In addition, the scanning protocol permitted a differentiation of two main stages of atherogenesis, termed (1) incident non-stenotic (early) atherosclerosis and (2) incident stenotic (advanced) atherosclerosis. The former was defined by the occurrence of new plaques in previously normal segments, the latter was defined by a relative increase in the maximum axial diameter of pre-existing plaques that exceeded the double measurement error of the method and a resulting narrowing of the lumen of more than $40 \%[39,40]$.

Validity and reproducibility of the ultrasound method applied have been described in detail elsewhere [39, 40]. Maximum efforts were made to avoid drifts in ultrasound assessments between 1990 and 1995. These included special training courses, continuous analyses for time trends in ultrasound assessments and carrying out all scans with the same equipment and by the same experienced sonographer.

Statistical analysis. All analyses were carried out by SPSS-X and BMDP software (Los Angeles, Calif., USA). Statistical evaluation of the association between risk factors and the category of glucose tolerance was based on chi-squared test, analysis of variance and analysis of covariance with sex, age, level of physical activity, smoking habits, daily alcohol intake and so- 
Table 1. Main clinical and biochemical features in the Bruneck Study cohort at baseline $(n=826)$

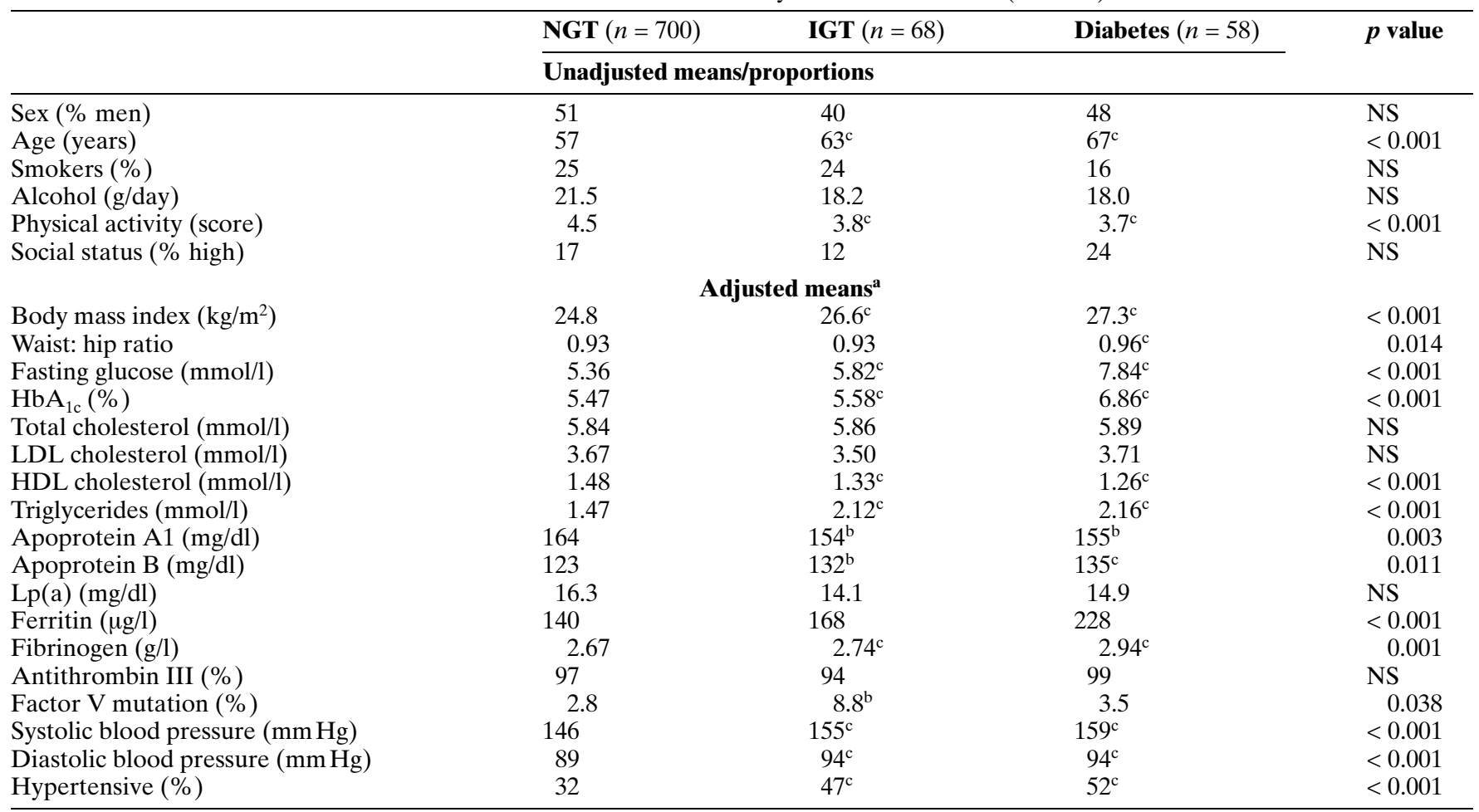

Sex, age, smoking, alcohol, physical activity and social status are unadjusted means or proportions. $P$ values were derived from analysis of variance or chi-squared test.

${ }^{a}$ Means were adjusted for sex, age, smoking, alcohol consumption, physical activity and social status. $P$ values were derived from analysis of covariance.
Pairwise comparisons of NGT vs IGT and NGT vs Type II diabetes were made with the Scheffe test which takes multiple comparisons into account (all pairs possible). ${ }^{\mathrm{b}} P<0.05$; ${ }^{\mathrm{c}} p<0.01$ cio-economic status used as covariates. Skewed variables were $\log _{\mathrm{e}}$-transformed to improve the approximation to a gaussian distribution. Pair-wise comparisons of IGT compared with normal glucose tolerance (NGT) and Type II diabetes compared with NGT were made by the Scheffe test [41], which takes into account multiple comparisons (all pairs possible) and thus is a conservative procedure.

The relation of IGT or Type II diabetes with 5-year changes in carotid atherosclerosis and with IMT was examined by standard linear regression analyses. Multivariate adjustment was done by forced entry of a fixed set of covariates, including potential confounders (age, sex, social status), typical vascular risk factors (hypertension, LDL cholesterol, smoking) and components of the metabolic syndrome associated with IGT or Type II diabetes (triglycerides, HDL cholesterol, BMI, fibrinogen).

Risk profiles of early and advanced carotid atherosclerosis were assessed by stepwise logistic regression analyses. The hypothesis test was based on likelihood-ratio statistics [42]. Separate equations were fitted for subjects without carotid atherosclerosis at the 1990 baseline (incidence of non-stenotic atherosclerosis during follow-up: yes vs no) and in those with pre-existing lesions (incident stenotic atherosclerosis during followup: yes vs no). The p values for entry and removal of variables, were set at 0.10 and $0.15[42,43]$. The analysis selected variables for inclusion among all those given in Table 1. Categories of glucose tolerance were modelled with indicator variables (set of dummy variables). Subjects with normal glucose tolerance were defined as the reference category (odds ratio $=1.0$ ).

\section{Results}

The prevalence of IGT in the cohort was $8.2 \%$ $(n=68$ out of 826$)$ and that of Type II diabetes $7.0 \%$ $(n=58)$ at baseline. Table 1 reports clinical and biochemical features of subjects with NGT, IGT and Type II diabetes at baseline. As expected, IGT and, to a greater extent, Type II diabetic subjects had greater BMI and WHR, higher triglycerides, apolipoprotein B, lower HDL cholesterol and apolipoprotein $\mathrm{A}$, and an increased proportion of hypertension. In addition these subjects also showed higher ferritin and fibrinogen concentrations.

Subjects with IGT and, to a greater extent, subjects with Type II diabetes had higher sex-adjusted and age-adjusted means atherosclerosis score in both $1990(p<0.001)$ and 1995 evaluations $(p<0.001)$. Also the mean changes in the atherosclerosis score during the follow-up were higher $(p<0.001)$ in IGT and Type II diabetes than in subjects with normal glucose tolerance (Fig.1). Linear regression analysis showed that 5-year change in the atherosclerosis score was related to IGT and Type II diabetes also after adjustment for smoking, LDL and HDL cholesterol, triglycerides, fibrinogen, hypertension and 


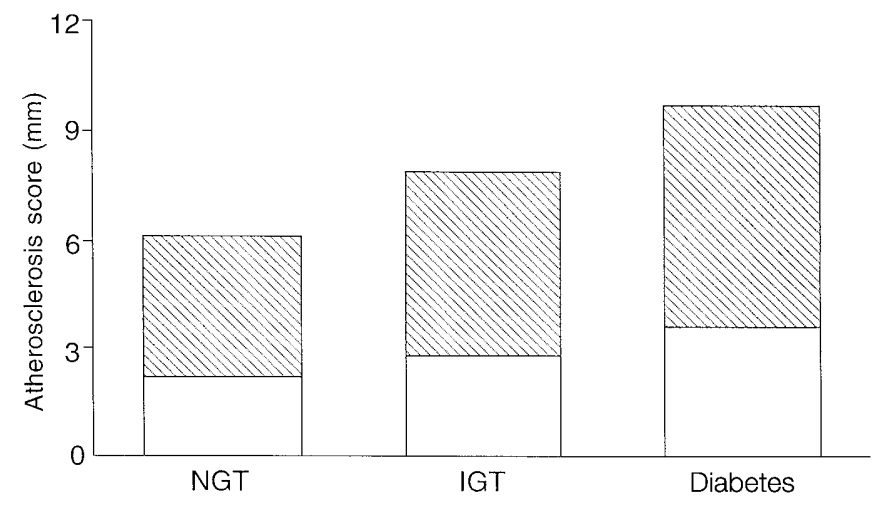

Fig. 1. Sex-adjusted and age-adjusted mean atherosclerosis scores in subjects with NGT, IGT and Type II diabetes mellitus from the Bruneck Study. The height of the bars represent mean scores at the end of follow-up. All differences (means in 1990, means in 1995 and mean changes in 1990-1995) were highly significant $(p<0.001), \square 1990, \mathbb{N}$ change in 1990-1995

BMI (Table 2). The use of means of covariates (1990-1995) in the analysis did not change the results [regression coefficients: IGT 0.645 (0.065 to 1.225$)$, $p=0.022$; Type II diabetes 0.734 (0.114 to 1.354 ), $p=0.010]$. Compared with models including only sex and age, regression coefficients of IGT and Type II diabetes declined by $12 \%$ and $25 \%$, respectively in the models including all classic risk factors.

Initima-media thickness was measured at the end of follow-up. Sex-adjusted and age-adjusted mean values of IMT in NGT, IGT and Type II diabetes were $0.975,1.032$ and $1.062 \mathrm{~mm}$, respectively $(p<0.05)$. When this surrogate measure of atherosclerosis replaced the 5-year change in the atherosclerosis score as outcome variable in the multiple linear regression analysis (Table 3 ) the associations of IMT with IGT and Type II diabetes only approached statistical significance $(p=0.07$ and 0.10$)$. The use of means of covariate (1990-1995) did not change the results [regression coefficients: IGT $0.048(-0.004$ to $1.000), p=0.106$; Type II diabetes $0.069(-0.004$ to $0.142), p=0.095]$. About one fifth of the relation between IGT or Type II diabetes and IMT appeared to be mediated by classic vascular risk factors.

All these results were consistent in men and women. For example, regression coefficients of 5-year progression of atherosclerosis were 0.89 and 0.99 for IGT and Type II diabetes in men, respectively $(p<0.05$ each; analysis adjusted for age and sex). The corresponding figures in women were 0.58 and $0.75(p<0.05$ each $)$. In non-smokers regression coefficients were 0.82 and 1.10 ( $p<0.01$ each).

In diabetic subjects no statistically significant association was found between the degree of glucose control (fasting glucose or $\mathrm{HbA}_{1 \mathrm{c}}$ at baseline or at follow-up or average of 1990 and 1995 determinations) and atherosclerosis progression or IMT. Likewise, diabetic subjects receiving oral hypoglycaemic agents
Table 2. Linear regression analyses of 5-year change in the atherosclerosis score (1990 to 1995) on IGT, Type II diabetes and potential vascular risk factors $(n=826)$

\begin{tabular}{|c|c|c|}
\hline Variable & $\begin{array}{l}\text { Regression coefficient } \\
(95 \% \text { CI) }\end{array}$ & $\overline{p \text { value }}$ \\
\hline $\begin{array}{l}\text { Unadjusted model } \\
\text { IGT }\end{array}$ & $1.090(0.469$ to 1.711$)$ & $<0.001$ \\
\hline Type II diabetes & 1.698 (1.039 to 2.357$)$ & $<0.001$ \\
\hline $\begin{array}{l}\text { Age/sex-adjusted mode } \\
\text { Age (per } 10 \text { years) }\end{array}$ & $0.787(0.641$ to 0.933$)$ & $<0.001$ \\
\hline Male sex & $0.799(0.487$ to 1.111$)$ & $<0.001$ \\
\hline IGT & $0.717(0.133$ to 1.301$)$ & 0.016 \\
\hline Type II diabetes & $0.908(0.279$ to 1.537$)$ & 0.004 \\
\hline $\begin{array}{l}\text { Multivariate model } \\
\text { Age (per } 10 \text { years) }\end{array}$ & $0.628(0.473$ to 0.783$)$ & $<0.001$ \\
\hline Male sex & $0.852(0.533$ to 1.171$)$ & $<0.001$ \\
\hline $\begin{array}{l}\text { Cigarette smoking } \\
\text { (yes vs no) }\end{array}$ & $0.714(0.347$ to 1.081$)$ & $<0.001$ \\
\hline $\begin{array}{l}\text { LDL cholesterol } \\
\quad(\text { per } 1 \mathrm{mmol} / \mathrm{l})\end{array}$ & $0.200(0.050$ to 0.350$)$ & 0.011 \\
\hline $\begin{array}{l}\text { HDL cholesterol } \\
\quad(\text { per } 1 \mathrm{mmol} / \mathrm{l})\end{array}$ & $-0.231(-0.459$ to -0.003$)$ & 0.048 \\
\hline Fibrinogen (per 1 g/l) & $0.679(0.379$ to 0.979$)$ & $<0.001$ \\
\hline Hypertension & 0.541 (0.176 to 0.906$)$ & 0.004 \\
\hline $\begin{array}{l}\text { Triglycerides } \\
\text { (per } 1 \mathrm{mmol} / \mathrm{l})\end{array}$ & $0.159(0.017$ to 0.301$)$ & 0.049 \\
\hline BMI (per $\left.1 \mathrm{~kg} / \mathrm{m}^{2}\right)$ & $0.007(-0.007$ to 0.014$)$ & 0.304 \\
\hline IGT & $0.631(0.049$ to 1.213$)$ & 0.034 \\
\hline Type II diabetes & $0.726(0.099$ to 1.353$)$ & 0.024 \\
\hline
\end{tabular}

The multivariate linear regression model was built by a forced entry of fixed set of covariates. Categorical variables were included as a set of dummy variables

faced a similar risk of atherosclerosis progression as those on diet or newly diagnosed: regression coefficients of 5-year change in atherosclerosis score 1.01 and 0.73 , respectively ( $p<0.05$ each).

There were 500 subjects free of atherosclerosis in 1990. Of these subjects, 451 had NGT (mean age 52 years, women $54 \%$ ), 31 had IGT (mean age 56 years, women $58 \%$ ) and 18 had Type II diabetes (mean age 64 years, women $61 \%$ ). Incident cases of non-stenotic atherosclerosis in these subjects were as follows: NGT 103 (22.8\%), IGT 15 (48\%), Type II diabetes $8(44 \%)$. Unadjusted odds ratios (OR) in the three categories were 1.0, 3.2 (95\% confidence intervals 1.5-6.6), 2.7 (1.1-6.9) $(p<0.001$ for differences). In a multivariate analysis the category of glucose tolerance lost its predictive significance. In this stepwise logistic regression model age, hypertension, ferritin, smoking (smoking-years), Lp(a), apolipoprotein $\mathrm{B}$, and heavy alcohol intake were identified as independent risk attributes of incident non-stenotic (early) atherosclerosis (Table 4). When means of covariates (1990-1995) were used in the multivariate model, the results were similar [OR: IGT 2.43 
Table 3. Linear regression analyses of intima-media thickness in 1995 on IGT, Type II diabetes and potential vascular risk factors $(n=826)$

\begin{tabular}{|c|c|c|}
\hline Variable & $\begin{array}{l}\text { Regression coefficient } \\
(95 \% \text { CI })\end{array}$ & $\overline{p \text { value }}$ \\
\hline $\begin{array}{l}\text { Unadjusted model } \\
\text { IGT }\end{array}$ & $0.097(0.032$ to 0.162$)$ & 0.004 \\
\hline Type II diabetes & $0.192(0.096$ to 0.288$)$ & $<0.001$ \\
\hline $\begin{array}{l}\text { Age/sex-adjusted model } \\
\text { Age (per } 10 \text { years) }\end{array}$ & $0.133(0.120$ to 0.146$)$ & $<0.001$ \\
\hline Male sex & $0.092(0.064$ to 1.120$)$ & $<0.001$ \\
\hline IGT & $0.057(0.004$ to 1.110$)$ & 0.046 \\
\hline Type II diabetes & $0.087(0.009$ to 0.135$)$ & 0.024 \\
\hline $\begin{array}{l}\text { Multivariate model } \\
\text { Age (per } 10 \text { years) }\end{array}$ & $0.118(0.104$ to 0.132$)$ & $<0.001$ \\
\hline Male sex & $0.099(0.070$ to 0.128$)$ & $<0.001$ \\
\hline $\begin{array}{l}\text { Cigarette smoking } \\
\text { (yes vs no) }\end{array}$ & $0.064(0.031$ to 0.097$)$ & $<0.001$ \\
\hline $\begin{array}{l}\text { LDL cholesterol } \\
\quad(\text { per } 1 \mathrm{mmol} / \mathrm{l})\end{array}$ & $0.030(0.015$ to 0.046$)$ & $<0.001$ \\
\hline $\begin{array}{l}\text { HDL cholesterol } \\
\quad(\text { per } 1 \mathrm{mmol} / \mathrm{l})\end{array}$ & $-0.027(-0.065$ to 0.011$)$ & 0.190 \\
\hline Fibrinogen (per $1 \mathrm{~g} / \mathrm{l})$ & $0.037(0.012$ to 0.055$)$ & 0.007 \\
\hline Hypertension & $0.072(0.039$ to 0.148$)$ & $<0.001$ \\
\hline $\begin{array}{l}\text { Triglycerides } \\
\text { (per } 1 \mathrm{mmol} / \mathrm{l})\end{array}$ & $0.009(-0.009$ to 0.018$)$ & 0.322 \\
\hline BMI (per $\left.1 \mathrm{~kg} / \mathrm{m}^{2}\right)$ & $0.001(-0.003$ to 0.005$)$ & 0.500 \\
\hline IGT & $0.046(-0.003$ to 0.105$)$ & 0.103 \\
\hline Type II diabetes & $0.072(-0.002$ to 0.146$)$ & 0.072 \\
\hline
\end{tabular}

The multivariate linear regression model was built by a forced entry of fixed set of covariates. Categorical variables were included as a set of dummy variables

(1.00-5.27), $\quad p=0.07 ; \quad$ Type II diabetes 0.93 (0.31-2.75), $p=0.89]$.

There were 326 subjects with pre-existing atherosclerosis in 1990. Of these subjects, 249 had NGT (mean age 65 years, women $40 \%$ ), 37 had IGT (mean age 69 years, women $62 \%$ ) and 40 had Type II diabetes (mean age 69 years, women $46 \%$ ). Incident stenosis above $40 \%$ (atherothrombosis) occurred in 54 subjects with NGT $(21.7 \%)$, in 17 with IGT $(45.9 \%)$ and in 21 with Type II diabetes $(52.5 \%)$. Unadjusted OR in the three categories were 1.0, $3.1(1.5-6.3), 4.0(2.0-7.9)(p<0.001$ for differences). In a multivariate logistic regression analysis Type II diabetes turned out to be the strongest independent predictor of advanced stenotic atherosclerosis (Table 5). Impaired glucose tolerance was significantly associated to carotid stenosis as well. When means of covariates (1990-1995) were used in the multivariate model, the results were almost identical [OR: IGT $2.72(1.22-6.11), p=0.002$; Type II diabetes $5.29(2.41-11.58), p<0.0001]$. The risk profile of advanced stenotic atherosclerosis was further composed of smoking (cigarettes/day), Lp(a) concentra-
Table 4. Risk profile of incident non-stenotic atherosclerosis in subjects free of carotid atherosclerosis at the 1990 baseline evaluation (early atherogenesis; $n=500$ )

\begin{tabular}{llr}
\hline Variable & OR (95\% CI) & P value \\
\hline Age (per 10 years) & $1.80(1.39-2.32)$ & $<0.001$ \\
Hypertension (yes vs no) & $2.41(1.43-4.06)$ & $<0.001$ \\
Ferritin (per 10 $\mu$ g/l) & $1.28(1.08-1.52)$ & 0.006 \\
Smoking-years (per 10 years) & $1.06(1.02-1.10)$ & 0.032 \\
Lp(a) (per 10 mg/dl) & $1.12(1.01-1.23)$ & 0.040 \\
Apolipoprotein B (per 10 mg/dl) & $1.08(1.01-1.16)$ & 0.041 \\
Alcohol consumption & & 0.045 \\
$\quad$ Abstainers & 1.00 & \\
1-50 g/day & $0.70(0.51-0.98)$ & 0.040 \\
51-99 g/day & $1.92(0.65-5.62)$ & 0.236 \\
$\quad$ 100 g/day & $2.16(1.07-4.37)$ & 0.036 \\
Glucose tolerance & & 0.114 \\
$\quad$ NGT $(n=451)$ & 1.00 & \\
IGT $(n=31)$ & $1.90(0.81-4.52)$ & 0.070 \\
$\quad$ Diabetes $(n=18)$ & $0.62(0.22-2.14)$ & 0.408 \\
\hline
\end{tabular}

OR were derived from forward stepwise logistic regression analyses which allowed for all variables given in Table 1. Alcohol consumption and glucose tolerance were modelled as indicator variables with the first category defined as the reference group (abstainers and NGT)

tions more than $32 \mathrm{mg} / \mathrm{dl}$, fibrinogen, age, factor $\mathrm{V}$ mutation, antithrombin III (low levels) and mild alcohol intake (inverse association). Notably, hypertension and apolipoprotein B (or other lipid variables) did not rank among these risk attributes. When IGT or Type II diabetes was associated with anyone of the prothrombotic factors (increased fibrinogen, low antithrombin III, factor V mutation, $\mathrm{Lp}(\mathrm{a})$ more than $32 \mathrm{mg} / \mathrm{dl}$, smoking) the occurrence of stenosis was remarkably increased (21 cases out of 31 subjects, i.e. $68 \%$ in 5 years).

\section{Discussion}

The concept that diabetes is associated with a pronounced increased risk of atherosclerotic cardiovascular disease is widely accepted [44]. The idea that increased cardiovascular disease risk is an attribute of diabetic hyperglycaemia has less consensus [22]. The few intervention trials aimed at reducing the risk of cardiovascular disease by control of hyperglycaemia did not achieve or only marginally achieved this goal [45-47]. On the other hand, it has been estimated that in diabetic subjects the typical risk factors (smoking, cholesterol, blood pressure) in concert account for no more than $25-30 \%$ of excess cardiovascular risk, thereby strongly suggesting that other undefined factors featuring the diabetic milieu could have a key role [48]. Furthermore, most epidemiological studies in this field targeted on clinical endpoints such as myocardial infarction, stroke, lower extremity amputation or cardiovascular death [8] and thus do not enable conclusions on atherogenic mechanisms in dia- 
Table 5. Risk profile of incident carotid stenosis (atherothrombosis) in subjects with pre-existing atherosclerosis at the 1990 baseline evaluation $(n=326)$

\begin{tabular}{llr}
\hline Variable & OR $(\mathbf{9 5} \% \mathbf{C I})$ & P value \\
\hline Glucose tolerance & & $<0.001$ \\
$\quad$ NGT $(n=249)$ & 1.00 & - \\
$\quad$ IGT $(n=37)$ & $2.80(1.20-6.35)$ & 0.009 \\
$\quad$ Diabetes $(n=40)$ & $5.01(2.28-11.08)$ & $<0.001$ \\
Smoking & & \\
(per 10 cigarette/day) & $1.98(1.37-2.88)$ & $<0.001$ \\
Lp(a) $>32$ mg/dl & $4.29(2.04-9.03)$ & $<0.001$ \\
Fibrinogen (per 1 g/l) & $2.31(1.39-3.86)$ & 0.001 \\
Age (per 10 years) & $1.79(1.22-2.64)$ & 0.003 \\
Alcohol consumption & & 0.005 \\
$\quad$ Abstainers & 1.00 & - \\
1-50 g/day & $0.39(0.18-0.88)$ & 0.023 \\
51-99 g/day & $1.05(0.42-2.76)$ & 0.737 \\
$\quad \geq 100$ g/day & $1.92(0.65-5.36)$ & 0.236 \\
Factor V mutation & $4.08(1.08-15.48)$ & 0.041 \\
Antithrombin III (per 10\%) & $0.80(0.66-0.98)$ & 0.042 \\
\hline
\end{tabular}

OR were derived from forward stepwise logistic regression analyses which allowed for all variables given in Table 1. Alcohol consumption and glucose tolerance were modelled as indicator variables with the first category defined as the reference group (abstainers and NGT)

betes to be drawn. In all, the precise pathogenic mechanisms linking diabetes and atherosclerosis are still a mystery.

In our study IGT or Type II diabetes showed an independent association with the progression of atherosclerosis (Table 2) but a modest association to early atherosclerosis which disappeared, however, after adjusting for typical vascular risk factors (Table 4). In other words, IGT or Type II diabetes was only of moderate relevance in early atherogenesis and its injurious effects were mediated, at least in part, by the risk complex associated with glucose intolerance. On the contrary, Type II diabetes was strongly and independently related to advanced stenotic atherosclerosis for which it constituted one of the leading risk conditions (Table 5). This association, which extended to IGT, was consistent in men and women, was independent of other vascular risk factors clustering with diabetes and persisted after adjusting for several potential confounders.

In recent years a number of studies attempted to make an objective evaluation of atherosclerosis by the use of imaging techniques. They yielded highly controversial results, with some studies indicating an independent association between atherosclerosis and diabetes [23, 49-56] and others obtaining no association at all [57-62]. The reason for the considerable heterogeneity in the results obtained is not yet clear but might include differences in the study cohorts and in the methods used to evaluate atherosclerosis, accuracy in defining the glucose tolerance status and in the assessment of confounding risk factors, as well as the type of statistical analysis. Results of previous studies are, however, not directly comparable to those of the current study given the differences in the study design. Except for three [49-51], the previous studies were not population-based. In addition, none of the previous studies yielded prospective data. Furthermore, atherosclerosis (plaques) was not accurately quantified but IMT was used as a precursor/surrogate measure in most of these studies. Wall thickening can, however, occur before atherosclerosis manifests (precursor lesion) but it also accompanies the atherogenic process, thereby reflecting atherosclerosis severity (surrogate lesion). Thus, results of studies using IMT as the outcome variable do not exclusively refer to the early stage of atherosclerosis but also to atherosclerosis in general. This might explain why IMT in our study and in other studies was a weaker correlate of diabetes. For instance in a recent paper from the investigators of the Insulin Resistance Atherosclerosis Study, only subjects with established Type II diabetes but not those with IGT or newly diagnosed Type II diabetes showed a marginally increased IMT after adjustment for confounding factors [63].

Only about one fifth of the association between Type II diabetes and atherosclerosis was mediated by classic vascular risk factors (metabolic complex). Furthermore, potential effects of diabetes on atherosclerosis was not related to the degree of glucose control or diabetes treatment. In other words, IGT or Type II diabetes seems to be associated with the progression of atherosclerosis independently of other vascular risk factors clustering with diabetes and also of the severity of hyperglycaemia.

Coagulation abnormalities have been proposed as a further potentially important pathophysiological link between glucose intolerance and atherosclerosis and arterial diseases, $[8,16,48,64]$. Several clues indicate that IGT or Type II diabetes represent a prothrombotic state due to a dysbalance between procoagulant and antithrombotic factors and between activators and inhibitors of plasminogen activation. Insulin resistance typical of IGT and Type II diabetes might contribute to this dysbalance $[65,66]$. In our study, stenosis higher than $40 \%$ was found to predominantly originate from atherothrombosis $[39,40]$ and to rest on a risk profile including almost exclusively factors directly or indirectly related to coagulation and fibrinolysis: fibrinogen, antithrombin III (higher concentrations being protective), Lp(a), factor V Leiden mutation, smoking, alcohol intake (protective if mild) (Table 5). Type II diabetes was the strongest single risk predictors in this analysis and IGT was of relevance as well. The associations remained highly significant even after adjusting for the above mentioned prothrombotic variables. It might be that the adverse effect of glucose intolerance on atherothrombosis is predominantly mediated by fac- 
tors of coagulation or fibrinolysis or both that we were not able to assess (e.g. plasminogen activator inhibitor-1). Notably, typical risk factors without procoagulant properties were not related to this advanced stenotic stage of atherosclerosis.

The Bruneck Study seems to be particularly suitable for investigating atherogenesis in diabetes on account of its high representativeness of the general population (near complete participation and followup), prospective design, assessment of several risk factors and potential confounders associated with diabetes, accurate identification of IGT and diabetes, and the extensive ultrasound assessments which enable standard analyses of diabetes effects on 5-year changes in carotid atherosclerosis to be carried out as well as special analyses addressing aetiologically distinct stages in the complex atherosclerosis process (atherothrombosis). In contrast to most previous studies, we have done an OGTT to identify IGT and undiagnosed Type II diabetes and to accurately distinguish these disorders from the condition of normal glucose tolerance. This is not a trivial point as many studies documented a substantial increase in cardiovascular disease in IGT and undiagnosed Type II diabetes $[7,8,22,67]$. Accordingly, in our study undiagnosed diabetic subjects carried a risk of carotid stenosis as high as that in diagnosed Type II diabetes (data not shown) and an increased risk was found in the IGT condition as well. Inclusion of these subjects in the reference group, as is unavoidable in studies limited to self-reported information on diabetes status or measurement of fasting blood glucose with no OGTT or both, could weaken or even eliminate true associations between Type II diabetes and atherosclerosis.

Our findings, with some caution, can be extrapolated to atherosclerosis in other vascular territories. Indeed, high coincidence exists between carotid atherosclerosis and both coronary and peripheral artery disease $[68,69]$. In addition, ultrasonographically determined carotid atherosclerosis and increased IMT are excellent risk predictors of cardiovascular events in longitudinal studies [70,71].

In conclusion, IGT and, to a greater extent, Type II diabetes are prominent risk predictors of 5-year progression of carotid atherosclerosis in this large prospective population survey. The associations obtained were at least in part independent of hyperglycaemia and other vascular risk factors featuring the diabetic milieu. Because Type II diabetes and IGT seem to be particularly strong risk attributes of advanced atherothrombotic stages in atherosclerosis, coagulation abnormalities could be a major culprit of cardiovascular disease in IGT or Type II diabetes. It is striking that the risk of advanced stenotic atherosclerosis in diabetes is amplified by the presence of other inherited or acquired coagulation disorders. About $70 \%$ of subjects with IGT or Type II diabetes and additional procoagulant risk factors developed carotid stenosis during the follow-up period of 5 years and, consequently, were at high risk of subsequent cardiovascular events. We suggest that strategies to prevent cardiovascular disease in IGT and Type II diabetes, in addition to a tight control of hyperglycaemia and other vascular risk factors, should focus on anti-thrombotic or anti-coagulant measures or both more vigorously than at present.

Acknowledgements. This work was supported by grants from the Italian National Research Council, the Italian Ministry of the University and Scientific and Technological Research and the Veneto Region (Progetto Sanitario Finalizzato).

\section{References}

1. Entmacher PS, Root HF, Marks HH (1964) The longevity of diabetic patients in recent years. Diabetes 13: 373-377

2. Kannel WB, McGee DL (1979) Diabetes and cardiovascular disease. The Framingham Study. JAMA 241: 2035-2038

3. Stamler R, Stamler J (1979) Asymptomatic hyperglycaemia and coronary heart disease: a series of papers by the international collaborative group, based upon studies in fifteen populations. J Chron Dis 32: 683-837

4. Fuller JH, Shipley MJ, Rose G, Jarrett RJ, Keen H (1983) Mortality from coronary heart disease and stroke in relation to degree of glycaemia: the Whitehall Study. BMJ 287: 867-870

5. Pan WH, Cedres LB, Liu K et al. (1986) Relationship of clinical diabetes and asymptomatic hyperglycaemia to risk of coronary heart disease mortality in men and women. Am J Epidemiol 123: 504-516

6. Most RS, Sinnock P (1983) The epidemiology of lower extremity amputations in diabetic individuals. Diabetes Care 6: 87-91

7. Jarrett RJ (1996) The cardiovascular risk associated with impaired glucose tolerance. Diabet Med 13:S15-S19

8. Laakso M, Lehto S (1977) Epidemiology of macrovascular disease in diabetes. Diabetes Rev 5: 294-315

9. Zavaroni I, Dall'Aglio E, Bonora E, Alpi O, Passeri M, Reaven GM (1987) Evidence that multiple risk factors for coronary artery disease exist in persons with abnormal glucose tolerance. Am J Med 83: 609-612

10. Vaccaro O, Rivellese A, Riccardi G et al. (1984) Impaired glucose tolerance and risk factors for atherosclerosis. Arteriosclerosis 4: 592-597

11. Goldberg RB (1981) Lipid disorders in diabetes. Diabetes Care 4: 561-572

12. Garg A, Grundy SM (1987) Diabetic dyslipidemia and its therapy. Diabetes Rev 5: 425-433

13. Fuller J (1985) Epidemiology of hypertension associated with diabetes mellitus. Hypertension 7 [Suppl 2]:S3-S7

14. Jarrett RJ (1990) Cardiovascular disease and hypertension in diabetes mellitus. Diabetes Metab Rev 5: 547-558

15. Juhan-Vague I, Alessi MC, Vague P (1996) Thrombogenic and fibrinolytic factors and cardiovascular risk in non-insulin-dependent diabetes mellitus. Ann Med 28: 371-380

16. Badimon JJ, Fuster V, Chesebro JH, Badimon L (1993) Coronary atherosclerosis: a multifactorial disease. Circulation 87 [Suppl 3]:III3-III16

17. McPhillips JB, Barrett-Connor E, Wingard DL (1990) Cardiovascular disease risk factors prior to the diagnosis of impaired glucose tolerance and non-insulin-dependent diabe- 
tes mellitus in a community of older adults. Am J Epidemiol 131: 443-453

18. Haffner SM, Stern MP, Hazuda HP, Mitchell BD, Patterson JK (1990) Cardiovascular risk factors in confirmed prediabetic individuals. Does the clock for coronary heart disease start ticking before the onset of clinical diabetes? JAMA 263: 2893-2898

19. Jarrett RJ (1984) Type II (non-insulin-dependent) diabetes mellitus and coronary heart disease: chicken, egg or neither? Diabetologia 26: 99-102

20. Stern MP (1996) Do non-insulin-dependent diabetes mellitus and cardiovascular disease share common antecedents? Ann Intern Med 124: 110-116

21. Gerstein HC, Yusuf S (1996) Dysglycemia and risk of cardiovascular disease. Lancet 347: 949-950

22. Barrett-Connor E (1997) Does hyperglycaemia really cause coronary heart disease? Diabetes Care 20: 1620-1623

23. Willeit J, Kiechl S (1993) Prevalence and risk factors of asymptomatic extra-cranial carotid artery atherosclerosis. A population-based study. Arterioscler Thromb 13: 661-668

24. Kiechl S, Willeit J, Rungger G, Egger G, Oberhollenzer F, Bonora E for the Bruneck Study Group (1998) Alcohol consumption and atherosclerosis: What is the relation? Prospective results from the Bruneck Study. Stroke 29: 900-907

25. World Health Organization (1985) Impaired glucose tolerance and diabetes. WHO criteria technical report series No 727, WHO, Geneva

26. World Health Organization (1978) Arterial Hypertension: Report of a WHO Study Group technical report series, No 628, WHO, Geneva

27. Carroll JJ, Smith N, Babson AL (1970) A colorimetric serum glucose determination using exokinase and glucose-6phosphate dehydrogenase. Biochem Med 4: 171-180

28. Siedel J, Hagel EO, Ziegenhorn J, Wahlefeld AW (1983) Reagent for the enzymatic determination of serum total cholesterol with improved lipolytic efficiency. Clin Chem 29: 1075-1080

29. Warnick GR, Benderson J, Albers JJ (1982) Dextran sulfate-Mg2 + precipitation procedure for quantitation of high density lipoprotein cholesterol. Clin Chem 28: 1379-1388

30. Wahlefeld AW (1974) Triglycerides. Determination after enzymatic hydrolysis. In: Bergmayer HU (ed) Methods of Enzymatic Analysis. Verlag Chemie and Academic Press, New York, pp 1831-1836

31. Friedewald WT, Levy RI, Fredrickson DS (1972) Estimation of the concentration of low-density lipoprotein cholesterol in plasma without use of preparative ultracentrifuge. Clin Chem 18: 499-502

32. Finck PC, Romer M, Haeckel R (1989) Measurement of proteins with the Behring Nephelometer. A multicenter evaluation. J Clin Chem Clin Biochem 27: 261-273

33. Willeit J, Kiechl S, Santer P et al. (1995) Lipoprotein (a) and asymptomatic carotid artery disease. Evidence of a prominent role in the evolution of advanced carotid plaques: the Bruneck Study. Stroke 26: 1582-1587

34. Cole RA, Soeldner JS, Dunn PJ, Bunn HF (1978) A rapid method for the determination of glycosilated haemoglobins using high-performance liquid chromatography. Metabolism 27: 289-301

35. Clauss A (1957) Gerrinnungsphysiologische schnellmethode zur bestimmung des fibrinogens. Acta Haematol 17: 237-246

36. Blasczyk R, Ritter M, Thiede C et al. (1996) Simple and rapid detection of factor $\mathrm{V}$ Leiden by allele-specific PCR amplification. Thromb Haemost 75: 757-759
37. Kiechl S, Willeit J, Egger G, Poewe W, Oberhollenzer F (1997) Body iron stores and the risk of carotid atherosclerosis: prospective results from the Bruneck Study. Circulation 96: 3300-3007

38. Crouse JR, Harpold GH, Kahl FR, Toole JF, McKinney WM (1986) Evaluation of a scoring system for extra-cranial carotid atherosclerosis extent with B-mode ultrasound. Stroke 17: 270-275

39. Kiechl S, Willeit J for the Bruneck Study Group (1999) The natural course of atherosclerosis. Part I. Incidence and progression. Arterioscler Thromb Vasc Biol 19: 1484-1490

40. Kiechl S, Willeit J for the Bruneck Study Group (1999) The natural course of atherosclerosis. Part II. Vascular remodeling. Arterioscler Thromb Vasc Biol 19: 1491-1498

41. Scheffe H (1953) A method for judging all contrasts in the analysis of variance. Biometrika 40: 87-104

42. Hosmer DW, Lemeshow S (1988) Applied logistic regression. John Wiley and Sons, New York

43. Bendel RB, Afifi A (1977) Comparison of stopping rules in forward regression. J Am Stat Assoc 72: 46-53

44. Stern MP (1997) Glycemia and cardiovascular risk. Diabetes Care 20: 1501-1502

45. University Group Diabetes Program (1982) Effects of hypoglycaemic agents on vascular complications in patients with adult-onset diabetes. VIII. Evaluation of insulin therapy. Final report. Diabetes 31 [Suppl 5]:S1-S26

46. Abraira C, Colwell JA, Nuttall FQ et al. (1995) Veterans Affairs Cooperative Study on glycemic control and complications in Type II diabetes (VA CSDM). Diabetes Care 18: 1113-1123

47. United Kingdom Prospective Diabetes Study Group (1998) Intensive blood-glucose control with sulphonylureas or insulin compared with conventional treatment and risk of complications in patients with Type 2 diabetes (UKPDS 33). Lancet 352: $837-853$

48. Bierman EL (1992) Atherogenesis in diabetes. Arterioscler Thromb 12: 647-656

49. Salonen R, Salonen JT (1991) Determinants of carotid intima-media thickness: a population-based ultrasonography study in Eastern Finnish men. J Intern Med 229: 225-231

50. O'Leary DH, Polak JF, Kronmal RA et al. (1992) Distribution and correlates of sonographically detected carotid artery disease in the Cardiovascular Health Study. Stroke 23: 1752-1760

51. Folsom AR, Eckfeldt JH, Weitzman S et al. (1994) Relation of carotid artery wall thickness to diabetes mellitus, fasting glucose and insulin, body size, and physical activity. Stroke 25: 66-73

52. Tell GS, Howard G, McKinney WM (1989) Risk factors for site specific extracranial carotid artery plaque distribution as measured by B-mode ultrasound. J Clin Epidemiol 42: 551-559

53. Whisnant JP, Homer D, Ingall TJ, Baker HL, Jr, O'Fallon WM, Wiebers DO (1990) Duration of cigarette smoking is the strongest predictor of severe extracranial carotid artery aherosclerosis. Stroke 21: 707-714

54. Fabris F, Zanocchi M, Bo M et al. (1994) Carotid plaque, aging and risk factors. A study of 457 subjects. Stroke 25 : 1133-1140

55. Wei M, Gonzales C, Haffner SM, O'Leary DH, Stern MP (1996) Ultrasonographically assessed maximum carotid artery wall thickness in Mexico City residents and Mexican Americans living in San Antonio, Texas. Association with diabetes and cardiovascular risk factors. Arterioscler Thromb Vasc Biol 16: 1388-1392

56. Bonora E, Tessari R, Micciolo R et al. (1997) Intimal-medial thickness of the carotid artery in nondiabetic and non-in- 
sulin-dependent diabetic subjects. Relationship with insulin resistance. Diabetes Care 20: 627-631

57. Crouse JR, Toole JF, McKinney WM et al. (1987) Risk factors for extracranial carotid artery atherosclerosis. Stroke 18: 990-996

58. Prati P, Vannuzzo D, Casaroli M et al. (1992) Prevalence and determinants of carotid atherosclerosis in a general population. Stroke 23: 1705-1711

59. Dempsy RJ, Moore RW (1992) Amount of smoking independently predicts carotid artery atherosclerosis severity. Stroke 23: 693-696

60. Parnetti L, Menculini G, Sabtucci A, Sabtucci C, Senin U (1993) Carotid atherosclerotic disease. Role of hypertension and other risk factors. Clin Exp Hypertens 15 [Suppl 1]: S 39-S 54

61. Prisant LM, Zemel PC, Nichols FT et al. (1993) Carotid plaque associations among hypertensive patients. Arch Intern Med 153: 501-506

62. Bonithon-Kopp C, Touboul PJ, Berr C, Magne C, Ducimetiere P (1996) Factors of carotid arterial enlargement in a population aged 59 to 71 years. The EVA Study. Stroke 27: 654-660

63. Wagenknecht LE, D'Agostino RB, Haffner SM, Savage PJ, Rewers M (1998) Impaired glucose tolerance, Type II diabetes and carotid wall thickness. The Insulin Resistance Atherosclerosis Study. Diabetes Care 21: 1812-1818
64. Jokl R, Colwell JA (1997) Arterial thrombosis and atherosclerosis in diabetes. Diabetes Rev 5: 316-330

65. Toft I, Bonaa KH, Ingebretsen OC, Nordoy A, Birkeland KI, Jenssen T (1997) Gender differences in the relationships between plasma plasminogen activator inhibitor-1 activity and factors linked to the insulin resistance syndrome in essential hypertension. Arterioscler Thromb Vasc Biol 17: 553-559

66. Trovati M, Mularoni EM, Burzacca S et al. (1995) Impaired insulin-induced platelet anti-aggregating effect in obesity and obese NIDDM patients. Diabetes 44: 1318-1322

67. Harris MI (1993) Undiagnosed NIDDM: Clinical and public health issues. Diabetes Care 16: 642-652

68. Craven TE, Ryu JE, Espeland MA et al. (1990) Evaluation of the associations between carotid artery atherosclerosis and coronary artery stenosis. A case-control study. Circulation 82: 1230-1242

69. O'Leary DH, Polak JF, Kronmal RA et al. (1996) Thickening of the carotid wall. A marker for atherosclerosis in the elderly? Stroke 27: 224-231

70. Salonen JT, Salonen R (1993) Ultrasound B-mode imaging in observational studies of atherosclerotic progression. Circulation 87 [Suppl 2]: S 56-S65

71. Bots ML, Hoes AW, Koudstall PJ, Hofman A, Grobbee DE (1997) Common carotid intima-media thickness and risk of stroke and myocardial infarction. The Rotterdam Study. Circulation 96: 1423-1437 